\title{
Mask industry assessment trend analysis: 2012
}

\section{Y. David Chan}

Y. David Chan, "Mask industry assessment trend analysis: 2012," Proc. SPIE 8352, 28th European Mask and Lithography Conference, 835203 (16 April 2012); doi: 10.1117/12.923746

SPIE Event: 28th European Mask and Lithography Conference (EMLC 2012), 2012, Dresden, Germany 


\title{
Mask Industry Assessment Trend Analysis: 2012
}

\author{
Y. David Chan \\ SEMATECH, 257 Fuller Road, Albany, USA 12203
}

\begin{abstract}
Microelectronics industry leaders consistently cite the cost and cycle time of mask technology and mask supply among the top critical issues for lithography. A survey was designed by SEMATECH with input from semiconductor company mask technologists and merchant mask suppliers to objectively assess the overall conditions of the mask industry. With the continued support of the industry, this year's assessment was the tenth in the current series of annual reports. This year's survey is basically the same as the 2005 through 2011 surveys. Questions are grouped into six categories: General Business Profile Information, Data Processing, Yields and Yield Loss Mechanisms, Delivery Times, Returns, and Services. Within each category is a multitude of questions that ultimately produce a detailed profile of both the business and technical status of the critical mask industry. We received data from 11 companies this year, which was a record high since the beginning of the series. The responding companies represented more than $96 \%$ of the volume shipped and about $90 \%$ of the 2011 revenue for the photomask industry. These survey reports are often used as a baseline to gain perspective on the technical and business status of the mask and microelectronics industries. They will continue to serve as a valuable reference to identify strengths and opportunities. Results can also be used to guide future investments in critical path issues.
\end{abstract}

Keywords: Mask industry, photomask, industry, mask yield, photomask yield, mask quality, photomask quality

\section{INTRODUCTION}

SEMATECH reinitiated a survey of the mask industry in 2002, intending to enhance the level of understanding of the unique and critical issues associated with the photomask industry. ${ }^{1}$ It planned to conduct the survey annually to provide a substantial and valuable reference database. This database has been built over time to help identify past trends and validate future projections. A similar survey had been done annually for seven years but was suspended after 1999 for because of lack of financial support to conduct it. The results from those past surveys were published as SPIE papers and presented at BACUS, where they were found to provide valuable insights for both mask makers and mask users. ${ }^{2,3}$ From 2002 to 2011, the survey questions remained essentially constant ${ }^{4-15}$. Questions are grouped into six categories: General Business Profile Information, Data Processing, Yields and Yield Loss Mechanisms, Delivery Time, Returns, and Services. Within each category are multiple questions that provide a detailed profile of both the business and technical status of the mask industry.

\section{ASSESSMENT APPROACH}

David Powell Consulting was the focal point for data collection. Participant identification markings were removed by them to make the raw data anonymous before the data were forwarded to the author. Data were requested from survey participants for the previous 12 months, from July 1 through June 30. The data were loaded into a spreadsheet and summarized for lowest, highest, and average values. Respondents received an Excel file with complete summary data for further analysis as an incentive for participation. 
The survey participants by years can be seen in the table below.

Table 1 - Participants by year

\begin{tabular}{|c|c|c|c|c|c|c|c|c|c|c|}
\hline Participants & 2002 & 2003 & 2004 & 2005 & 2006 & 2007 & 2008 & 2009 & 2010 & 2011 \\
\hline Advanced Mask Technology Center & & YES & & W/Toppan & W/Toppan & & YES & & YES & YES \\
\hline Compugraphics International Ltd & YES & YES & YES & YES & YES & YES & YES & YES & YES & YES \\
\hline Dai Nippon Printing & YES & YES & YES & YES & YES & YES & YES & YES & YES & YES \\
\hline Toppan Photomasks Inc/DuPont Photomasks Inc & YES & YES & YES & W/Toppan & w/Toppan & W/roppan & wrioppan & wroppan & wroppan & W/Toppan \\
\hline Hoya & & YES & YES & YES & YES & YES & YES & YES & & YES \\
\hline Hynix & & & & & & & & & YES & YES \\
\hline IBM & YES & YES & & & & & & & & YES \\
\hline Intel Mask Operation & YES & YES & YES & YES & YES & YES & YES & YES & YES & YES \\
\hline Micron Technology Mask Shop & & & YES & & & & & & & \\
\hline Photronics Inc & & & YES & YES & & & & YES & YES & YES \\
\hline Samsung & & & & & YES & & & & & \\
\hline Semiconductor Manufacturing International Company (SMIC) & & & & & YES & YES & ES & YES & YES & YES \\
\hline Taiwan Mask Shop (TMC) & YES & YES & YES & YES & YES & YES & YES & YES & YES & \\
\hline Toppan Printing & & YES & YES & YES & YES & YES & YES & YES & YES & YES \\
\hline Taiwan Semiconductor Manufacturing Company, Ltd. & YES & YES & YES & YES & YES & YES & YES & YES & YES & YES \\
\hline Total Respondents & 7 & 10 & 10 & 8 & 9 & 8 & 9 & 9 & 10 & 11 \\
\hline
\end{tabular}

Description of survey sections:

1. General Mask Profile Information

This section seeks to establish a general description of the basic elements of the mask business: technology groundrule categories; application types (logic, memory, microprocessors, etc.); mask types by glass size (PSM, binary, OPC); magnification distribution; and distribution of fabrication methods used for patterning. The type of pellicle is also included.

2. Data Processing

This section requests data on file size and data preparation time average, maximum, and $95^{\text {th }}$ percentile of each respondent's distribution. For the fifth time, write time data were gathered. The $95^{\text {th }}$ percentile is requested to help discern what file sizes and write times are truly representative of the norm without having extraordinarily large, anomalous files over weighted in the analysis.

3. Yields and Yield Loss Mechanisms

Overall yield by glass size and mask type (binary, phase-shifting method) is given. Fifteen yield loss mechanisms are offered to generate an industry Pareto chart. Binary and phase shift mask losses were separated since the 2007 survey.

4. Delivery Time

Data on average delivery time and time for the first three layers of a new mask set are collected by four different mask type categories: binary, binary with moderate to aggressive optical proximity correction (OPC), attenuated, and alternating phase shift masks Note: Attenuated phase shift masks are also known as embedded phase shift masks or half-tone phase shift masks. Alternating phase shift masks are also known as strong phase shift masks or hard shifted masks.

5. Mask Returns

This section collects data on mask returns according to nine categories.

6. Mask Service

"Mask maintenance" services are divided into eight service categories. 


\section{DATA}

NOTE: Comparisons among the surveys may not be totally accurate since the surveys represent a different cross-section of the overall industry (as seen in Table 1). In addition, not all participants answered every question. Where possible and appropriate, the results from the 2003 to 2011 surveys have been volume-weighted. All 2002 results are averaged by respondents. Graphs with 2002* have data that are volume-weighted except for 2002. Charts with 2002 are simple averages by response for all years.

1. General Mask Profile Information

- Mask volume for the $<45 \mathrm{~nm}$ nodes increased at an approximate growth rate of $70 \%$ from 2007 to 2011 . Despite the economic turmoil in 2008 and 2009, the high-end device makers continue their investments in node advancement. There were also significant increases in mask volume for the $\geq 250 \mathrm{~nm}$ node in 2010 and 2011 , indicating a number of relevant products at the mature nodes. The economic problem in 2008 and 2009 encouraged many products and application innovations with the mature technology.

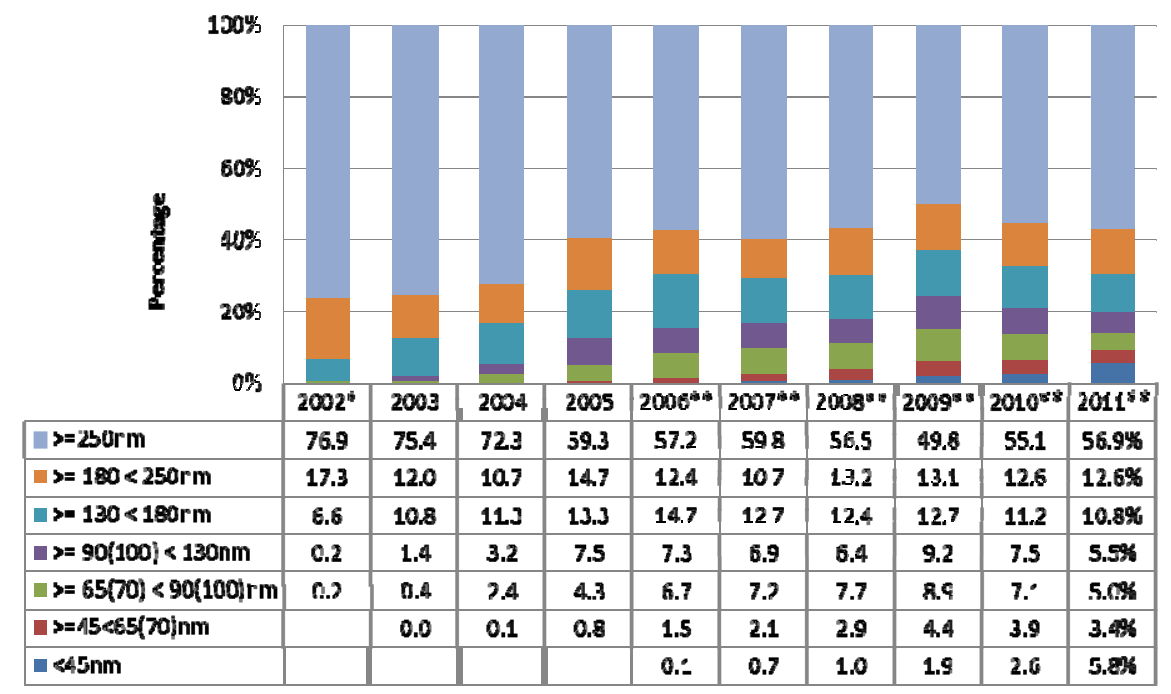

- Logic designs are still driving the majority of the mask volume. The device landscape is changing, perhaps due to our endless appetite for mobile applications. The memory percentage is now trending up after some recent decline while the microprocessor suffered a significant decline in 2011. The RF/mixed signal and system-on-achip (SOC) product percentages remained stable. More data points are needed to see whether the trends will be sustained.

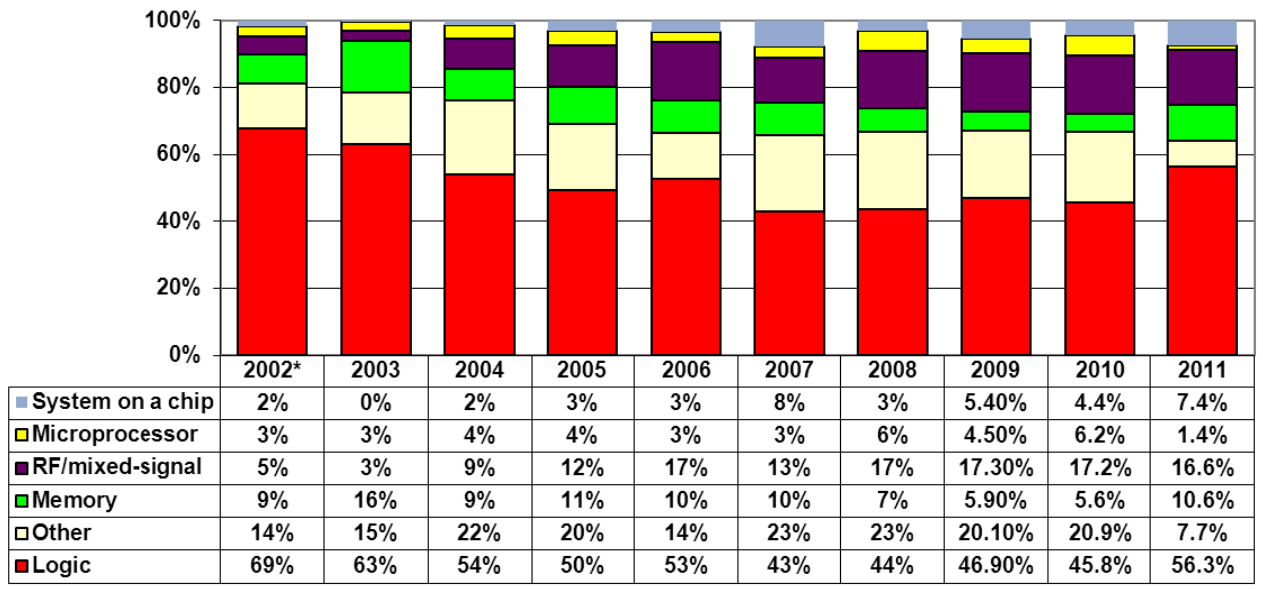


- More than $84 \%$ of photomasks are currently made on the 6025 format. Over the last five years, this percentage has steadily increased. (Note: The question was asked differently in 2002; therefore, no comparative data are available.) The mask volume for the $5 \mathrm{X}$ magnification is about the same as $4 \mathrm{X}$ for the first time in 2011 . This could be indicative that some older generation wafer steppers are beginning to be retired.
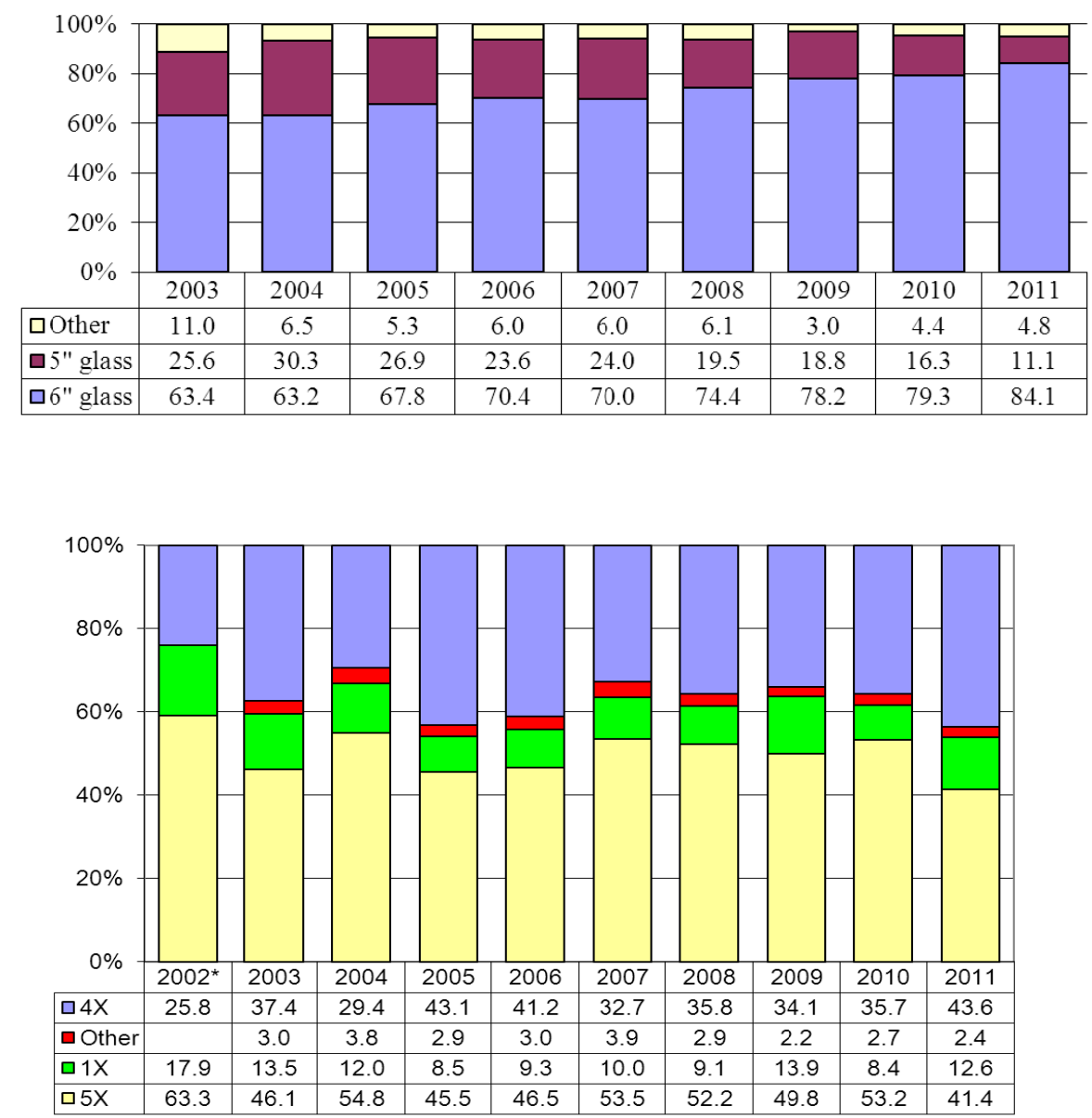

- The production phase-shifting masks (PSMs) have been exclusively made on 6-inch masks. Alternating PSM volume has remained very low. Attenuated mask type is stable $\sim 10-12 \%$. The participant mix could cause a certain amount of year-to-year fluctuations.

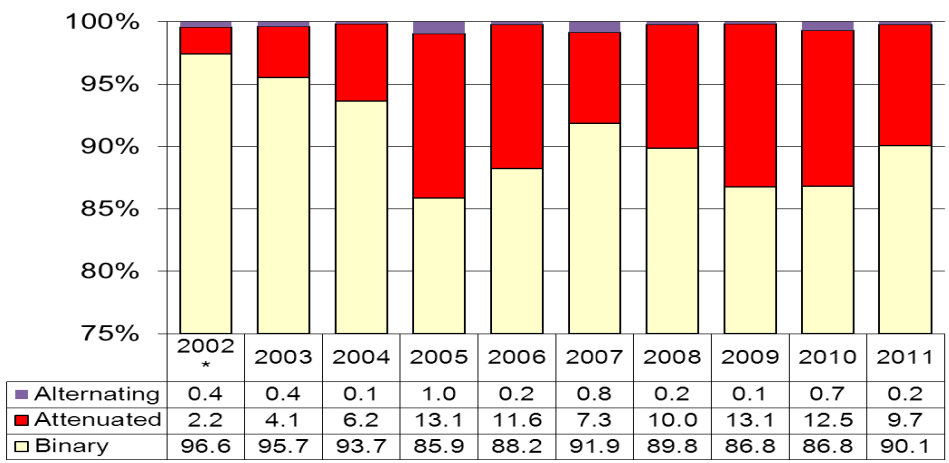


- Aggressive optical proximity correction (OPC) was growing at a steady pace until a significant drop in 2011. The no OPC category also had a significant jump in 2011 after stabilizing at $~ 70 \%$ in from 2007 to 2010 . There are two possible explanations: 1) year-to-year participants varied, and 2) according to ITRS 2011 edition, single optical exposure has reached its limit at $40 \mathrm{~nm}$ half-pitch (hp $)^{16}$. Today, $32 \mathrm{~nm}$ hp flash devices are being manufactured using double patterning as a way of extending the half-pitch while keeping the numerical aperture and wavelength constant. Transition from single patterning to DP may temporarily provide relief from aggressive OPC. More data points are needed to see whether the trends can be sustained.

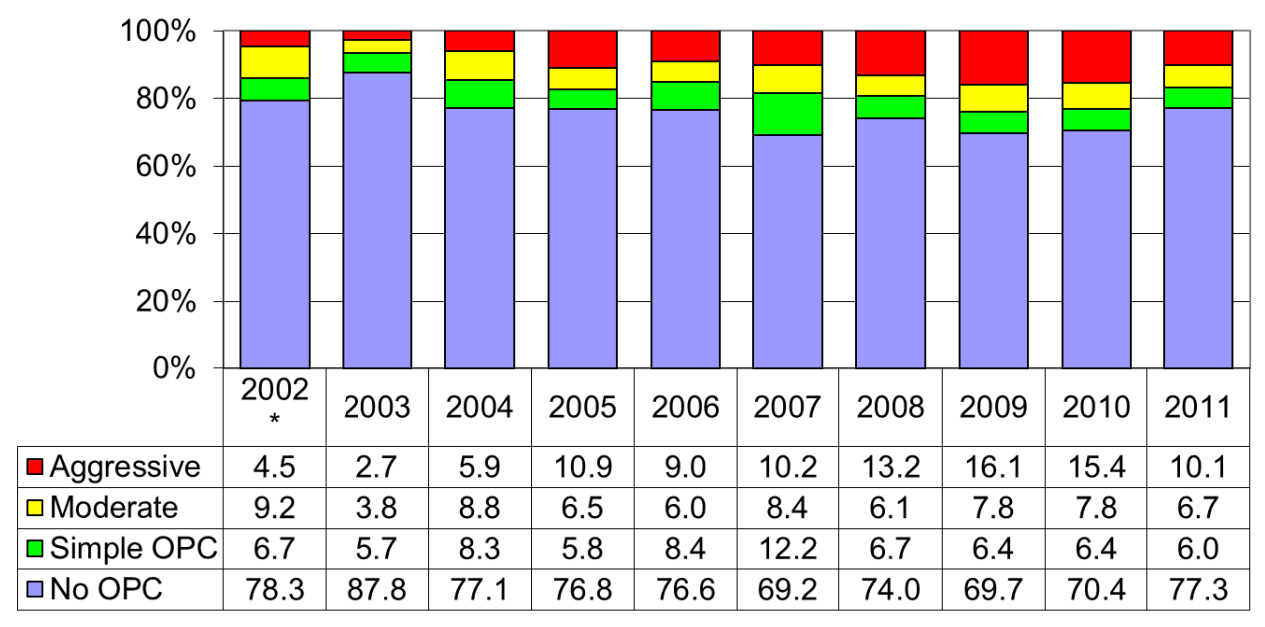

- Pellicle usage seems to remain flat over the years with a two-year higher than normal usage in the "no pellicle" category. This could be an artifact of the change in the mix of mask shops represented by the survey. There seems to be upward trends for both DUV and I-line pellicle usage, which could directly result from $\geq 250 \mathrm{~nm}$ node volume increase.

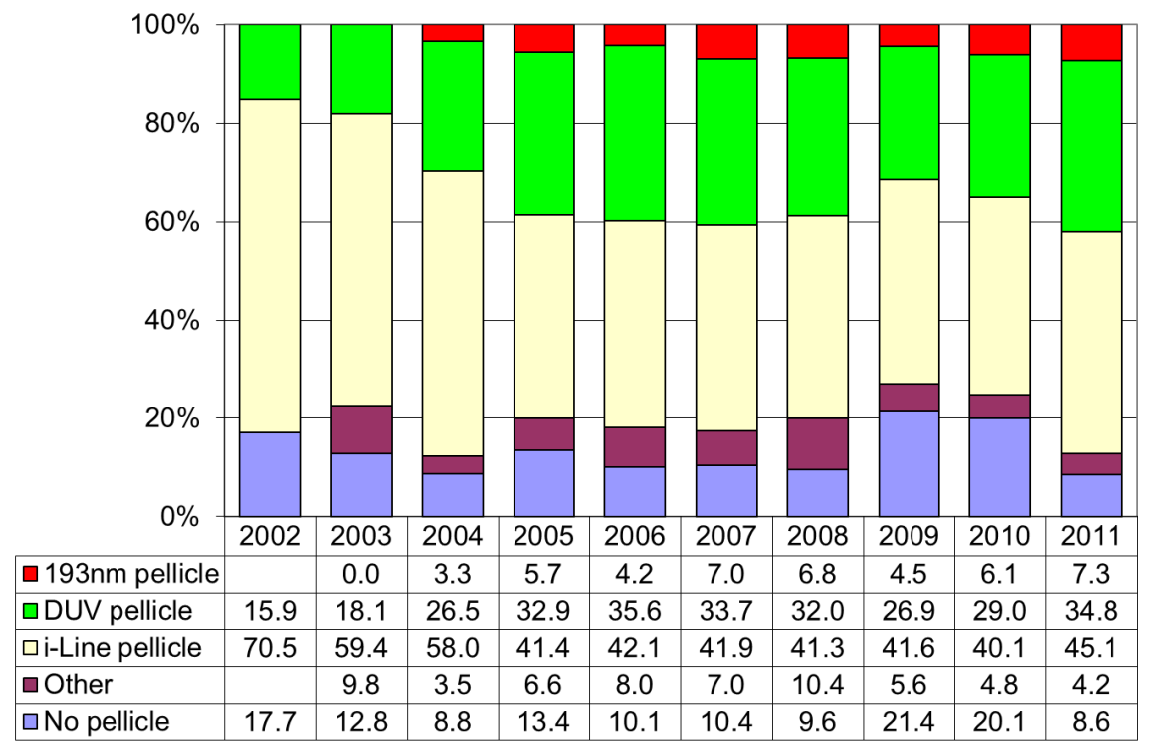

- The combined volumes for the raster spot e-beam tools and the $\leq 50 \mathrm{kV}$ shaped e-beam tools have been steadily declining in favor of the high voltage shaped e-beam tools. Increase in the usage of laser patterning tools is related to the increase in $\geq 250 \mathrm{~nm}$ products. 


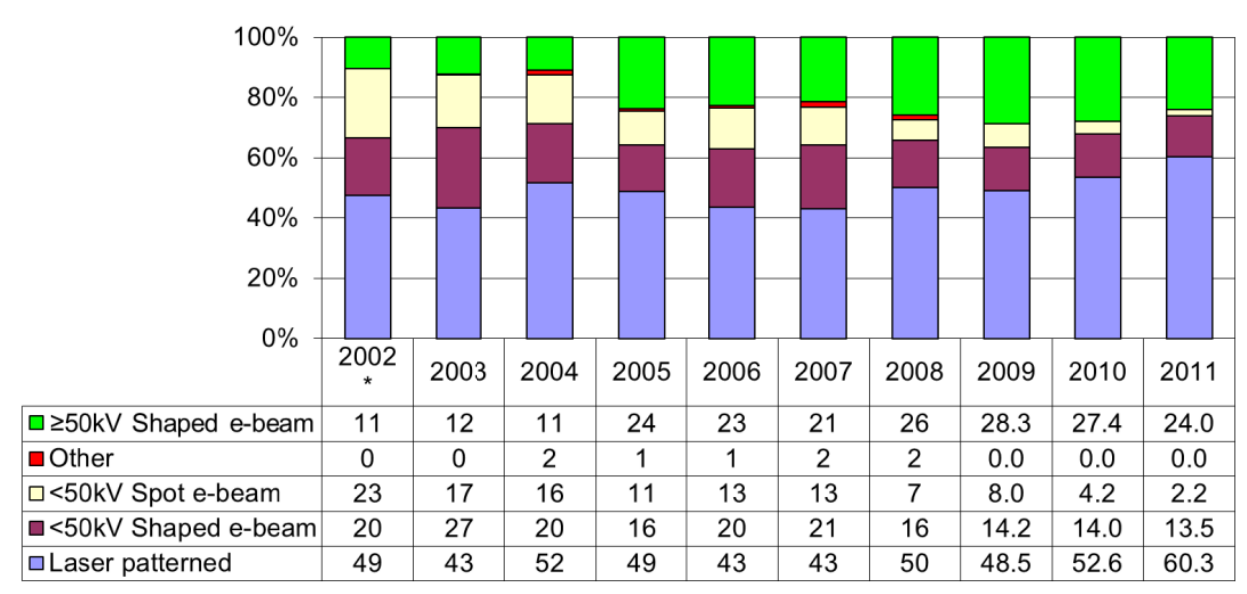

- The volume percentages for optical metrology tools using $<300 \mathrm{~nm}$ wavelength were stable from 2006 through 2010. The reason for the significant increase in 2011 is not clear. Innovative optical means could be deployed to replace SEM measurements. More data points are needed to see whether we have a real trend. We may subsequently need to have a better breakdown in this category.

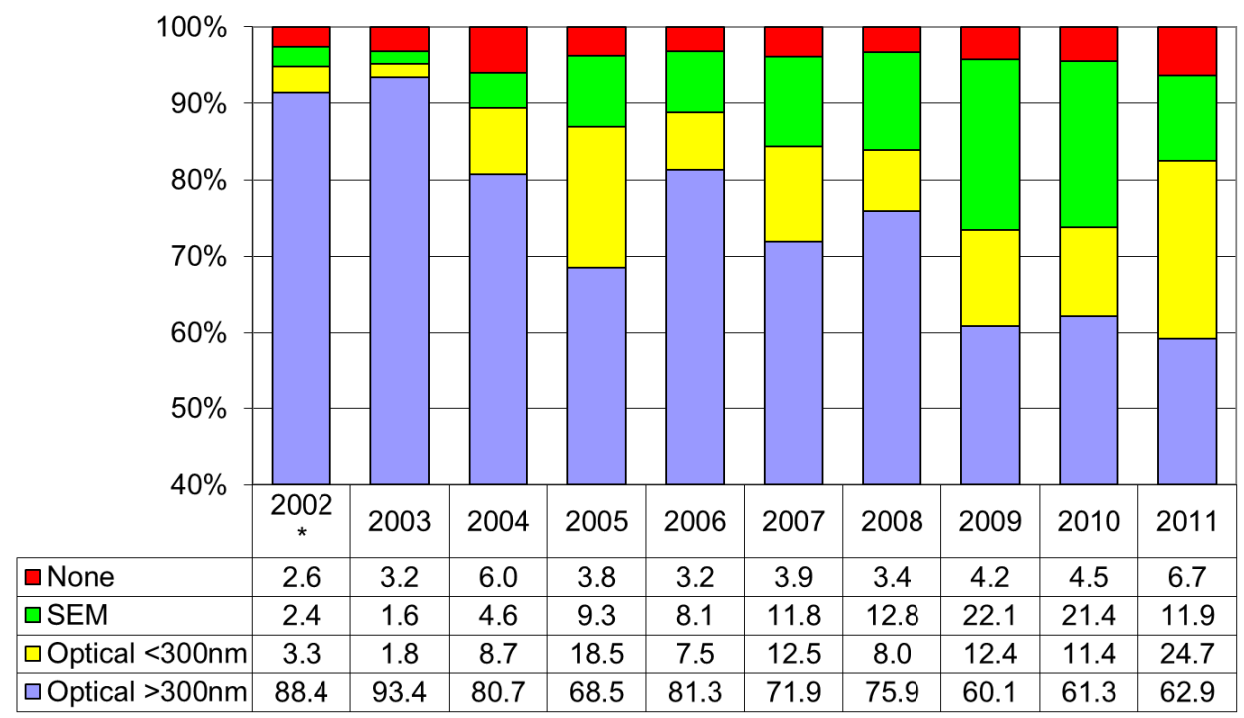

- The percentages of die:database and die:die were essentially the same from 2006 through 2010 . The die:database increased dramatically in 2011, perhaps due to the increase in multi devices/shuttle in wafer lots. 


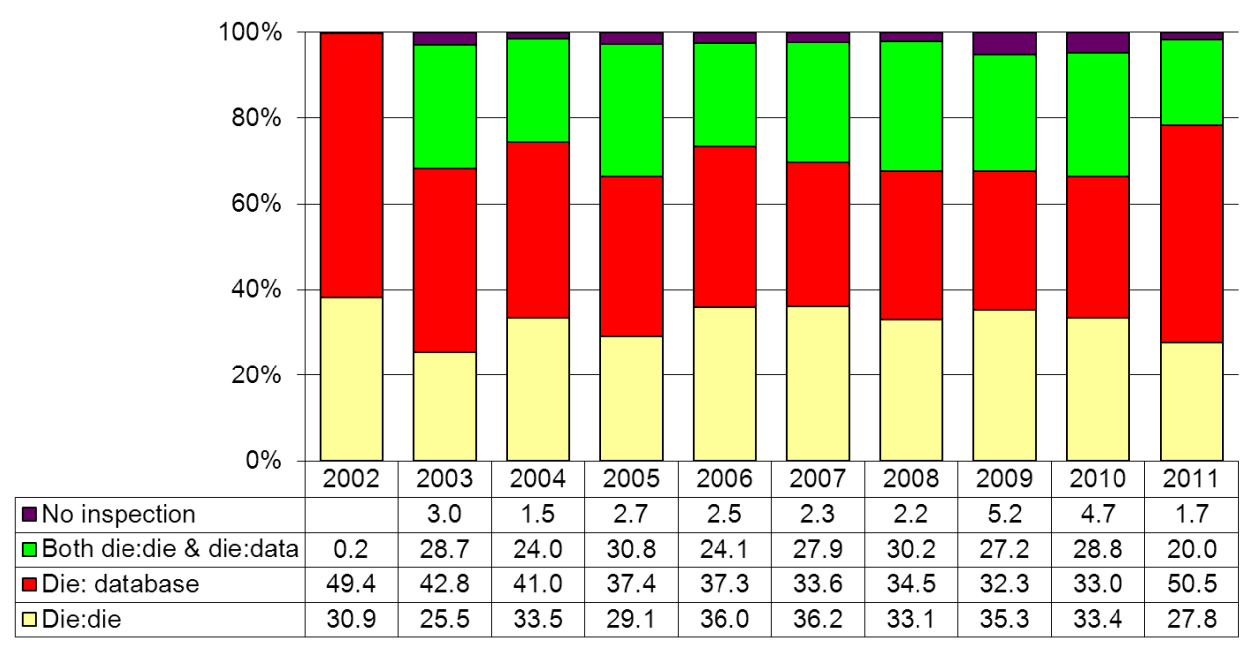

- The no repair percentage had been stable from $\sim 35 \%$ to $\sim 40 \%$ with a big jump in 2011 . This could be the result of record yield (see below) and the mature technology volume increase in 2011. The use of e-beam repair steadily increased from 2007 to 2010 and then declined slightly in 2011. This is more likely due to the disproportionate increase in mature technology volume than in high-end volume. More data points are needed to better see the trend.

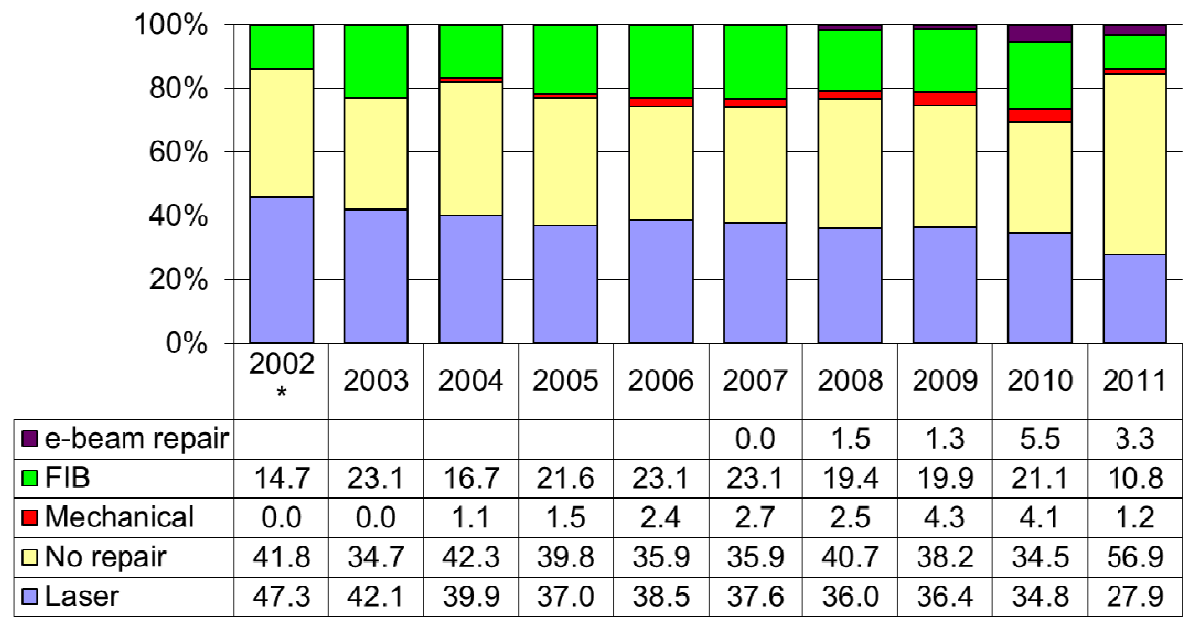

- Design data file size averages and $95^{\text {th }}$ percentiles are increasing at a steady pace of $1.4 \mathrm{X}$ per year over the ten years of the survey. This represents a growth of over $3 \mathrm{X}$ over the last four years. 


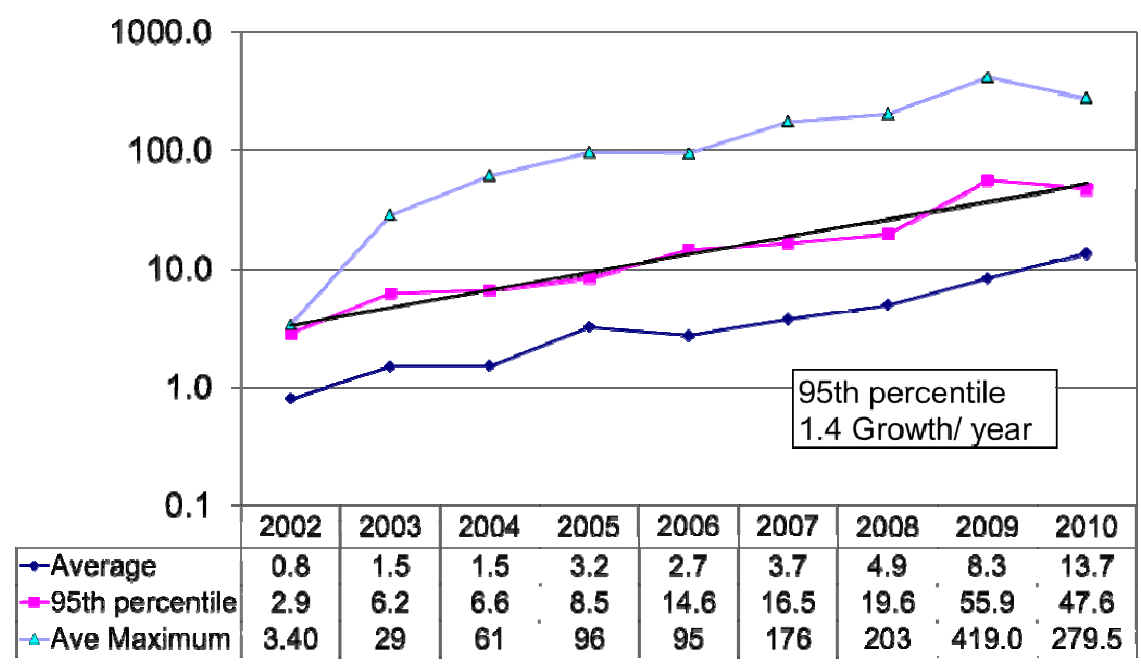

- Patterning write time has been gathered since 2007. The average is dominated by the laser patterning tool while the $95^{\text {th }}$ percentile represents the e-beam patterning write time. Even though the data volumes have been increasing consistently since 2002,2010 was the first year when the $95^{\text {th }}$ percentiles write time increased significantly (44\%). This might imply that e-beam mask writers were not able to keep up with the increasing data volume in 2010. Such a challenge may have subsequently been resolved as the $95^{\text {th }}$ percentile write time in 2011 did not increase.

\begin{tabular}{|l|c|c|c|c|c|}
\cline { 2 - 6 } \multicolumn{1}{c|}{} & 2007 & 2008 & 2009 & 2010 & 2011 \\
\hline Ave Write Time, Hr. & 2.8 & 3.1 & 2.6 & 3.7 & 3.3 \\
\hline 95th Percent & 5.6 & 5.5 & 5 & 7.2 & 7.6 \\
\hline Max Write TIme & 25.4 & 22.9 & 25.3 & 28.8 & 33.2 \\
\hline
\end{tabular}

- Data preparation CPU processing times are starting to increase again, but more data points are needed in future years.

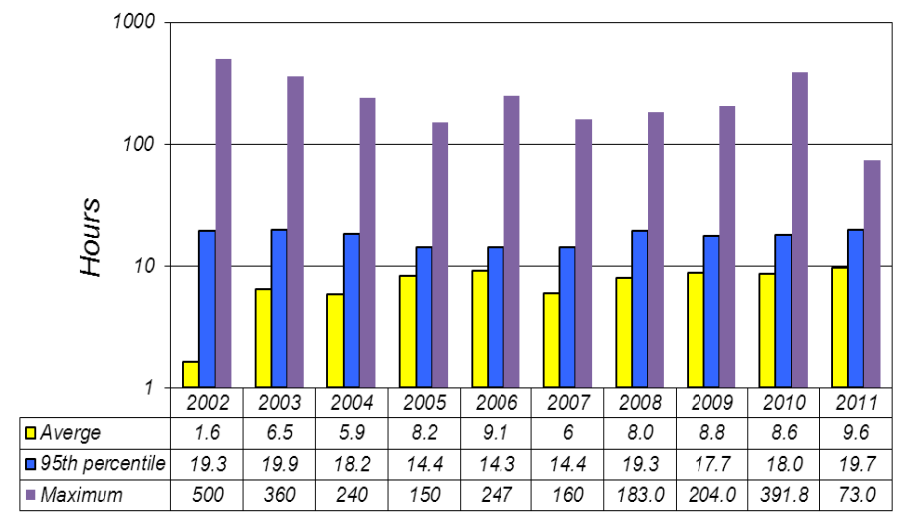

- The average yield for binary masks was at a record high of $97.6 \%$ in 2011 . Yields have been slowly increasing over the last six years. 


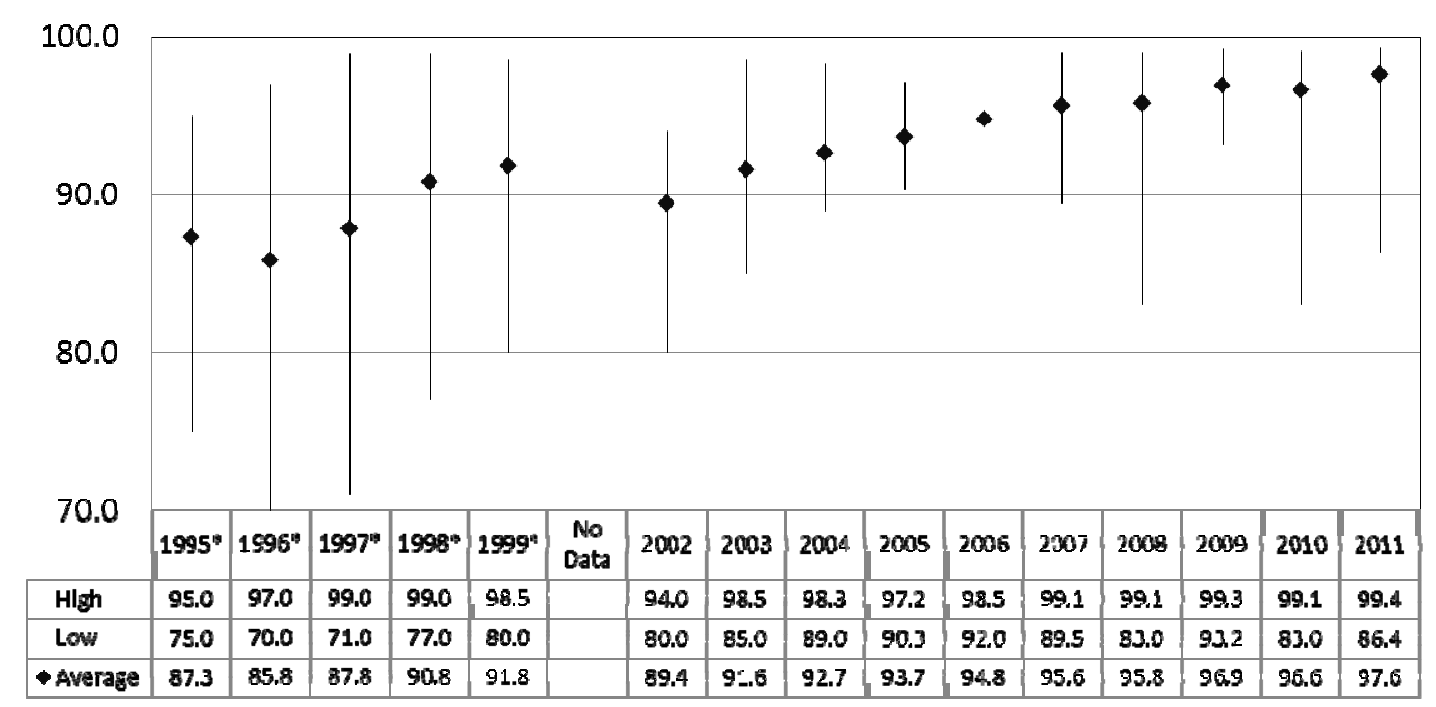

*Represents survey years (July to June). The 1995 to 1999 data are any data available in the calendar year reported in the 1999 BACUS survey paper by Brian Grenon.

- The 6-inch PSM yields have generally increased over the last four years. Record yields were achieved for all three mask categories in 2011.

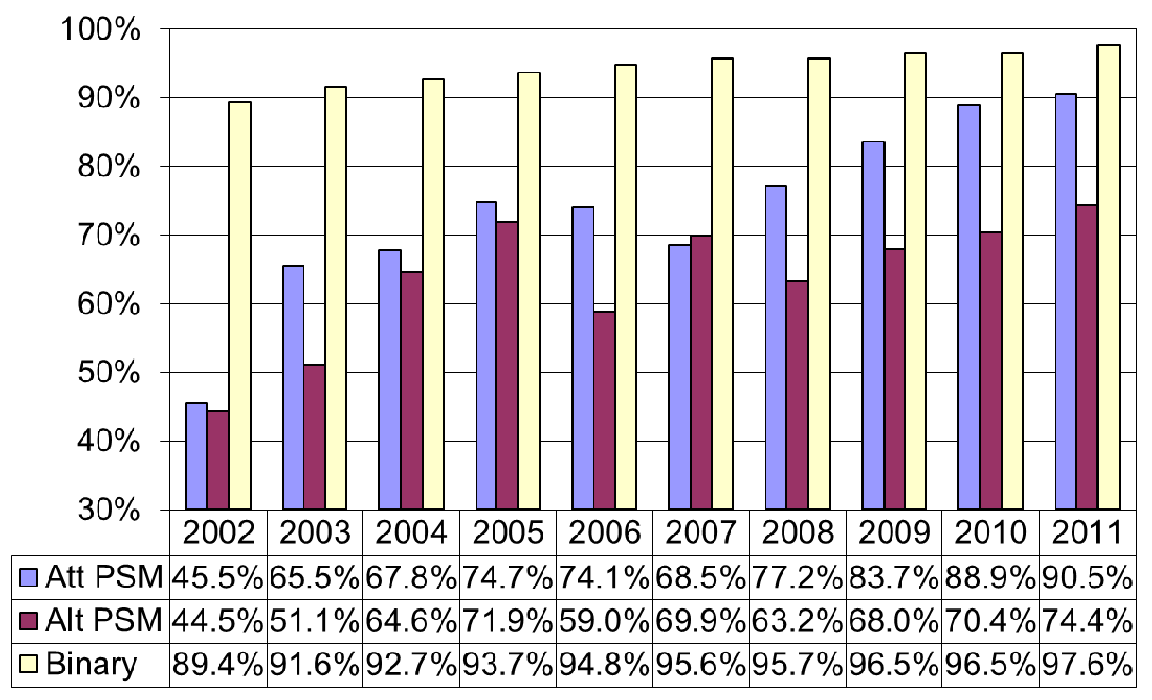

- The major process-related yield loss mechanisms are essentially constant from year to year. Hard defects account for more than half of the yield loss. Human errors (administrative and manufacturing errors) are stable at about $15 \%$. Critical dimension (CD) mean-to-target is always higher than uniformity and could perhaps benefit from the feed backward/forward protocols often used in wafer fabs. The chart below combines binary and PSM losses. 


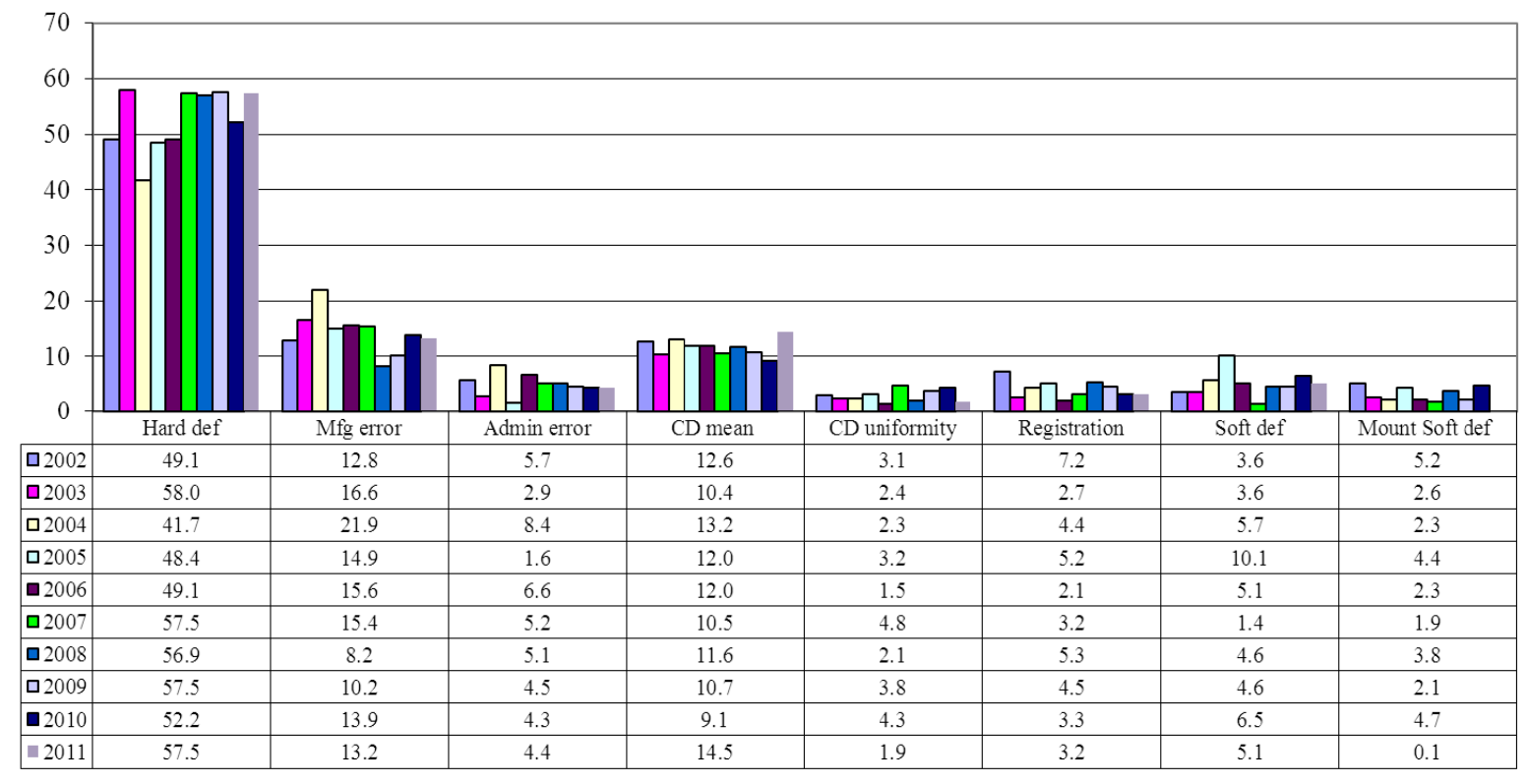

- Delivery times vary significantly by the types of masks. Experience anticipates this as the yields are the major driver for delivery times. OPC masks take longer to manufacture due to their increased complexity and write times. Both attenuated and alternating PSMs take longer because of additional lithography and processing steps as compared to binary masks. In general, delivery times have been stable even though the content and complexity are increasing.

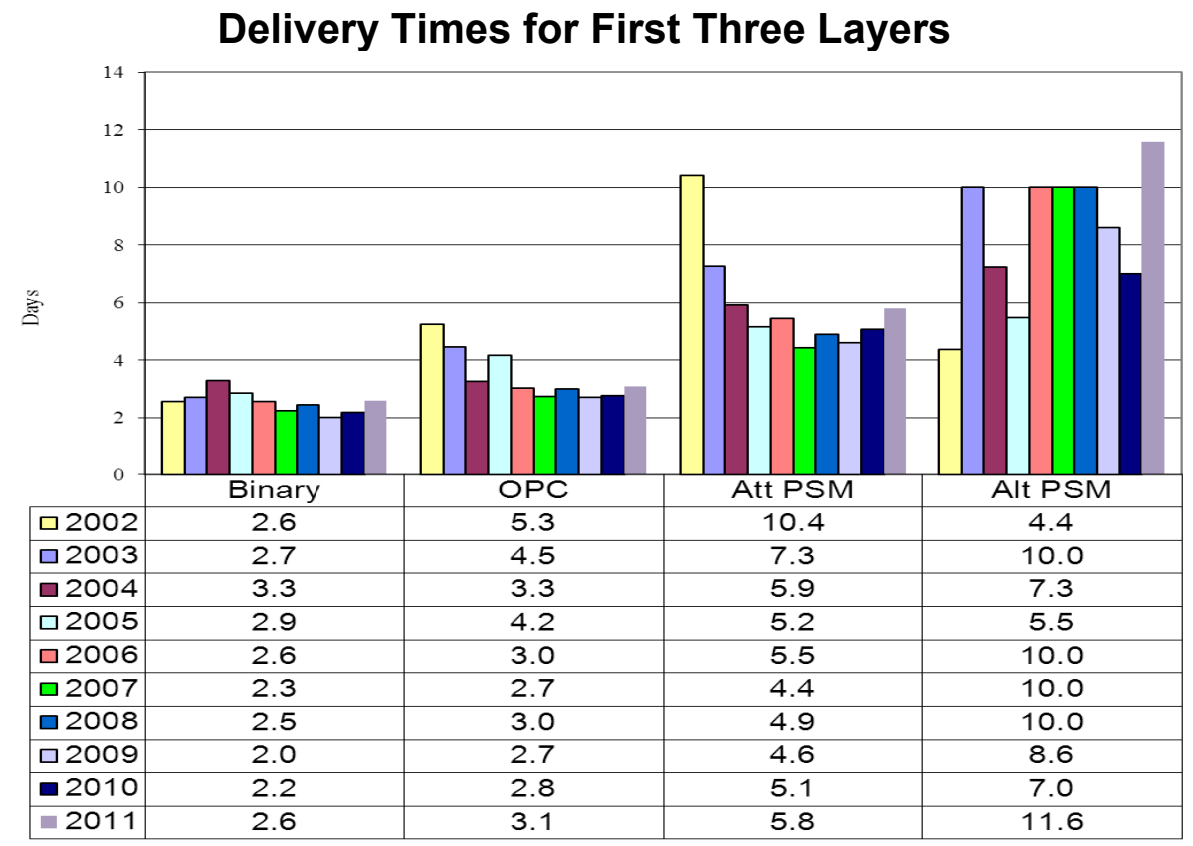

- As expected, the delivery times for the first three layers are better than the average delivery times. 


\section{Average Delivery Times}

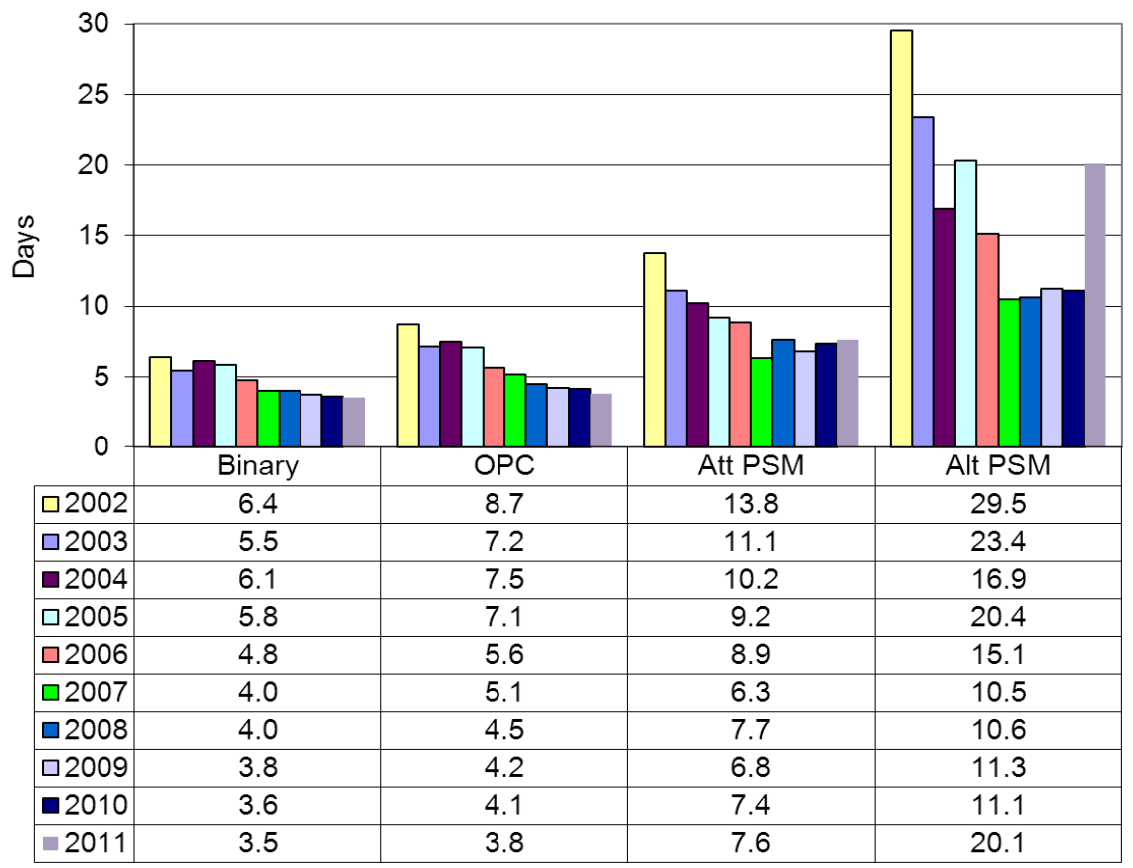

- Mask maintenance service was required most often for replacing damaged pellicles. Retraining of in-fab reticle handling procedures may be needed. The "other" category is growing at a significant pace and needs to be refined as new categories in future year's surveys.

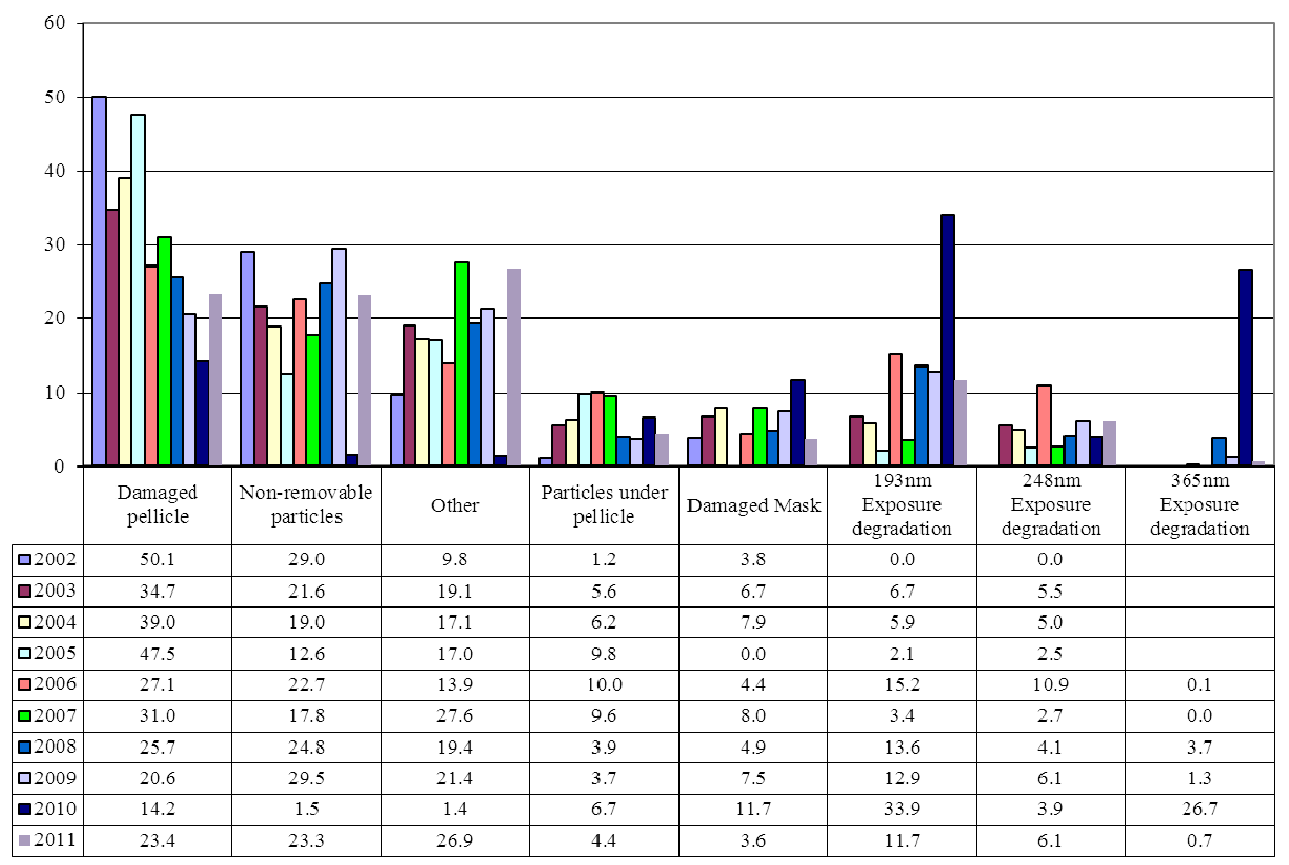


- When the 2011 photo-induced degradation service rates are normalized with the percentage of masks shipped, there is a strong dependence on exposure wavelengths. The normalized damage rate for $193 \mathrm{~nm}$ is $9 \mathrm{X}$ that of $248 \mathrm{~nm}$ and $100 \mathrm{X}$ of $365 \mathrm{~nm}$.

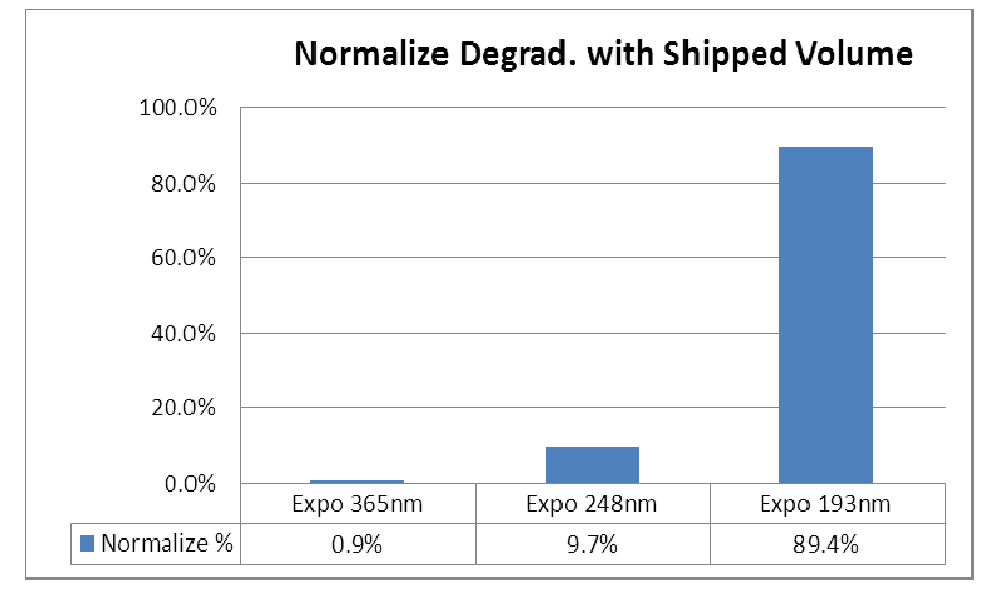

\section{CONCLUSIONS}

We received survey data from 11 companies this year, which was a record high since the beginning of the series. The responding companies represented more than $96 \%$ of the mask volume shipped and about $90 \%$ of the 2011 revenue for the photomask industry. This database provided a good understanding of the state of the photomask industry.

The economic downturn from 2008 to 2009 and our unsatiated appetite for mobile applications have a lasting impact on the landscape of the photomask industry. Mask volume increased significantly for the $\geq 250 \mathrm{~nm}$ nodes in 2010 and 2011, indicating a number of relevant and innovative products using the mature nodes. The high-end device makers continue their investments in shrinking feature sizes. The mask volume for the $<45 \mathrm{~nm}$ nodes continued to increase at an approximate growth rate of $70 \%$ from 2007 to 2011. While Logic designs are still driving the majority of the mask volume, the memory percentage is now trending up and microprocessors trending downward. The percentage of $\mathrm{RF} /$ mixed signal and SOC products remains stable. More data points are needed to see whether such trends can be sustained.

Mask yields for binary, EAPSM, and AAPSM are at an all-time high. Hard defects continue to be the major factor in yield loss, cost, and delivery time. Data file sizes continue to increase with the $95^{\text {th }}$ percentile at a growth rate of $1.4 \mathrm{X} /$ year. The productivity of e-beam writers must continuously be improved to maintain the current level of write time and keep pace with growing file sizes. Data preparation times vary among respondents, which may reflect the different industry segments addressed by each mask maker.

\section{ACKNOWLEDGEMENTS}

The authors heartily thank the participating companies, Advanced Mask Technology Center, Compugraphics International Ltd., Dai Nippon Printing, Hoya, Hynix, IBM, Intel Mask Operation, Photronics, Semiconductor Manufacturing International Company (SMIC), Taiwan Mask Shop, Toppan Printing, and Taiwan Semiconductor Manufacturing Company, Ltd., for their spirit of cooperation in providing this valuable data to the industry. The authors also thank Dede Adams at David Powell Consulting, Inc. for her role in data collection and Greg Hughes for his past contributions.

Most importantly, we would like to thank SEMATECH and its member companies for their funding support and the technical assistance and guidance provided in the generation of this paper. 


\section{REFERENCES}

1. K.R. Kimmel, “A Mask Industry Assessment: 2002," $22^{\text {nd }}$ Annual Symposium on Photomask Technology and Management BACUS, Proceedings of SPIE Vol. 4889 Part 1, pp. 1-14, 2002.

2. B.J. Grenon, "1999 Mask Industry Quality Assessment," $15^{\text {th }}$ Annual Symposium on Photomask Technology and Management BACUS, Proceedings of SPIE Vol. 3873, pp. 162-174, 1999.

3. E. Gonzalez-La'O, "1998 Mask Industry Quality Assessment," Proc. SPIE $14^{\text {th }}$ Annual Symposium on Photomask Technology and Management BACUS, Proceedings of SPIE Vol. 3546, pp. 10-29, 1998.

4. B.J. Grenon, Mask Makers Data Book, 2002 Edition, published by Grenon Consulting, Inc., 2002.

5. K.R. Kimmel, “A Mask Industry Assessment: 2003," $23^{\text {rd }}$ Annual Symposium on Photomask Technology and Management BACUS, Proceedings of SPIE Vol. 5256, pp. 331-43, 2003.

6. G. Shelden and S. Hector, "Mask industry Assessment, 2004," Photomask Technology Conference, Proceedings of SPIE Vol. 5567, pp. 1-12, 2004

7. G. Shelden and S Hector, "Mask industry Assessment, 2005," Photomask Technology Conference, Proceedings of SPIE Vol. 5992, 2005

8. G. Shelden and P. Marmillion, "Mask industry Assessment, 2006," Photomask Technology Conference, Proceedings of SPIE 6349-2, 2006

9. G. Shelden, P. Marmillion and G. Hughes, "Mask industry Assessment, 2007," Photomask Technology Conference, Proceedings of SPIE 6730-2, 2007

10. G. Hughes, H. Yun, “Mask industry Assessment, 2008," Photomask Technology Conference, Proceedings of SPIE 7122-02, 2008.

11. G. Hughes, H. Yun, “Mask industry Assessment, 2009," Photomask Technology Conference, Proceedings of SPIE 7488-2, 2009.

12. G. Hughes, H. Yun, "Mask Industry Assessment Trend Analysis: 2010,” 26th European Mask and Lithography Conference, Proceedings of SPIE 7545-2, 2010.

13. G. Hughes, D. Chan, "Mask industry Assessment, 2010," Photomask Technology Conference, Proceedings of SPIE 7823-3, 2010.

14. G. Hughes, D. Chan, "The 2002 to 2010 Mask Survey Trend Analysis," $27^{\text {th }}$ European Mask and Lithography Conference, Proceedings of SPIE 7985-1, 2011.

15. Y. D. Chan, "Mask Industry Assessment: 2011," Photomask Technology Conference, Proceedings of SPIE 8166-2, 2011.

16. International Technology Roadmap for Semiconductors, 2011 Edition, Lithography Chapter. 